\title{
Functional Simulation of Human Blood Identification Device using Feed-Forward Artificial Neural Network for FPGA Implementation
}

\author{
Denny Darlis, Heri Murwati, Rizki Ardianto Priramadhi, Mohamad Ramdhani \\ Telkom University \\ Bandung, Indonesia \\ denny.darlis@tass.telkomuniversity.ac.id
}

\begin{abstract}
The identification of human blood type still requires a fast and accurate device considering the number of blood samples that need to be distributed and transfused immediately. In this study we propose a hardware implementation of human blood type identification devices using feedforward neural network algorithms on grayscale images of blood samples. The images to be used are $32 \times 32$ pixels, $48 \times 48$ pixels, 64x64, 80x80, and 9x96 pixels. The algorithm were implemented using VHSIC Hardware Description Language. With artifical neural network implemented on Xilinx FPGA Spartan 3S1000, the success rate of detection by grouping by the mean and median ratios of the number of ' 1 ' bits is more than $75 \%$.
\end{abstract}

Keywords-feedforward propagation; artificial neural network; FPGA; human blood type identification

\section{INTRODUCTION}

During this time blood type testing is often used by the ABO method which is manually processed. according to the ABO blood grouping system, the blood is divided into 4 groups, namely $\mathrm{A}, \mathrm{B}, \mathrm{AB}$, and $\mathrm{O}$. The determination of human blood type using reagent fluid called antisera is antisera $\mathrm{A}$ and antisera B. Antisera fluid is then mixed in human blood sample blood groups can be determined from the clumping results. This will certainly become more complicated and require more attention if the blood sample to be tested is quite large. To accelerate the process of determining this blood type, the image of each antisera given by antisera can be determined using an electronic device that is able to distinguish each tested blood sample.

In [1] artificial neural network was simulated using MATLAB Image Processing toolbox for edge detection. For blood type identification using ABO, [2], [3]already simulate the image processing method using MATLAB. Meanwhile, in [4] feedforward neural network was implemented in efficient hardware using Xilinx FPGA series 4000. For ABO method, [5] also implemented the ANN using FPGA Spartan Series. In other way, [6] blood type identification also can be implemented using low cost microcontroller such as ATMEGA 8535. And in [7], [8] red blood cell was detected and counted using another method such as fuzzy logic and hough transform.
In this paper, a functional simulation for human blood identification using $\mathrm{ABO}$ method are presented with image processing for targeting on Xilinx Spartan 3S1000 FPGA implementation.

\section{SySteM DESIGN}

\section{A. Preprocessing}

Preprocessing in the first training image is done by changing the image type from RGB to Grayscale and then to Black and White. After that we convert the image so that the value of binary 1 is changed to binary value 0 , and vice versa. Then the obtained binary image will be used as input on the backpropagation algorithm

In the test image there is only one preprocessing block that is different from preprocessing on the training image, which is contained in the block converting RGB to Grayscale. In the test image block the section is filled with $\mathrm{YCbCr}$ block to Grayscale as shown on Table 1.

\section{B. Feature Extraction}

The process to get the image feature is done on the FPGA with the binary image input of the preprocessing result. Feature is simply obtained by counting the number of binary bits 1 in each image of blood sample either on anti A or anti B.

TABLE 1 EXAMPLE OF BLOOD SAMPLE IMAGE ON ANTI A AND

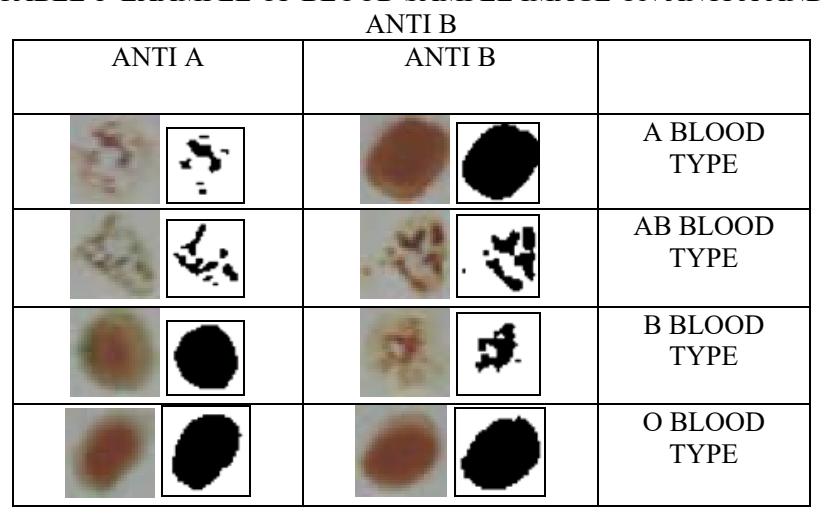




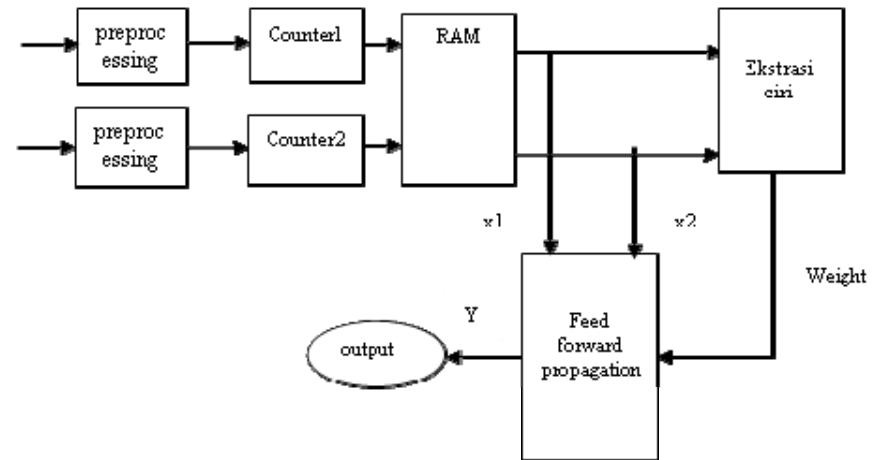

Fig. 1 Diagram Block of ANN System targeting on FPGA

\section{Back Propagation}

The algorithm to be used is feedforward propagation for backpropagation with binary sigmoid activation as shown on Fig. 1. In this training algorithm has one hidden layer. The input used is the result of feature extraction with binary 1 image counting to the output of the preprocessing result. There are two input vectors on the input layer derived from the binary image of the anti A and anti B samples. The input is the result of binary image calculation 1 as shown on Fig. 2 .

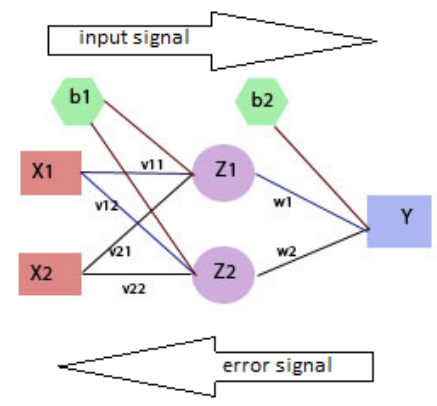

Fig. 2. Algorithm flow chart for designed system

\section{IMPLEMENTATION}

A. RTL Simulation

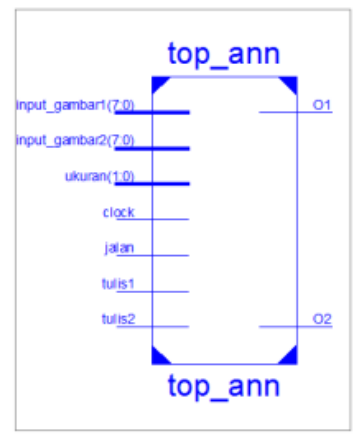

Fig. 2 Top Level Block

\section{1) Preprocessing}

This pre block is the first block that processes the incoming input. In this block the input is an 8-bit vector compared to the threshold gray level used. Threshold values are also inverted as shown on Fig. 3.

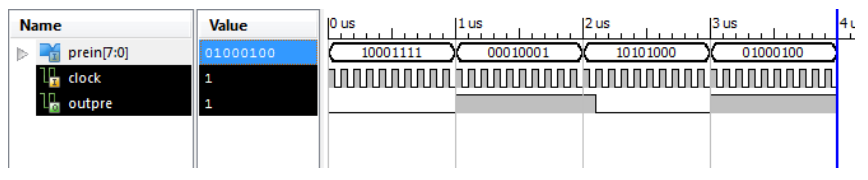

Fig. 3 Preprocessing simulation results

\section{2) Control counter}

In the control_counter program there are two programs that include counters and memory. The functional simulation is shown on Fig. 4.

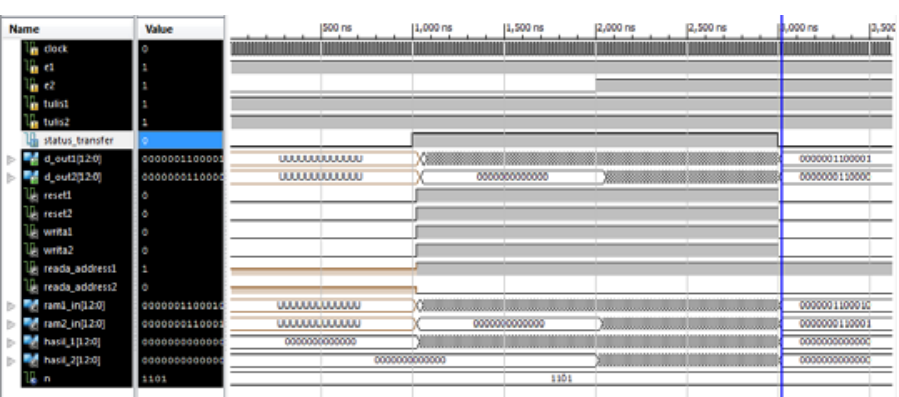

Fig. 4 control_counter simulation results

\section{3) Counter}

Program counter is used to perform bit counting ' 1 ' from incoming input from pre block. Designed two counter blocks used in conjunction with the number of image inputs entered in the system

\section{4) Memory}

The memory used is dual input and dual output. The function of the memory itself is to temporarily save the result and calculate the result will be issued condition has been fulfilled.

\section{B. Feature grouping}

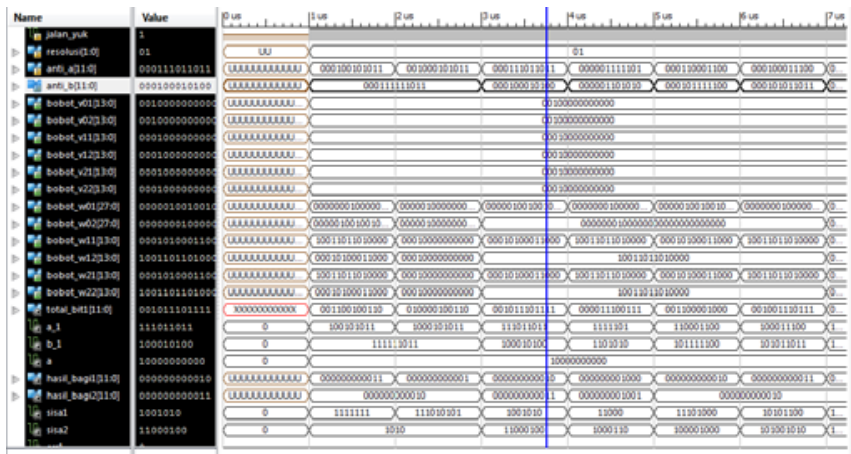

Fig. 5 Simulation result of feature grouping

The incoming input into the grouping or pattern selection program is the result of counter bit ' 1 ' from input to the control_counter program. Then the pattern that has been obtaine $\overline{\text { di }}$ in the scenario is used to determine the weights that correspond to the pattern. These weights are used in the forward propagation process to test inputs entered and 
determine the type of group (A, B, AB, or $\mathrm{O})$ as shown on Fig. 5 .

\section{Feedforward propagation}

Feedforward propagation or forward propagation is part of the backpropagation algorithm. This process is applied for targeting Xilinx Spartan 3S1000 FPGA.

The input comes from two previous blocks, the weight and the bit count ' 1 ' (anti a and anti b) results. The first calculation result (x1) and the result of the second calculation (x2) will be multiplied by the weight. To get a result on neuron1, $\mathrm{x} 1$ multiplied by $\mathrm{v} 11$, whereas $\mathrm{x} 2$ multiplied by $\mathrm{v} 21$. The multiplication result is then added and added by weight v01 (bias1). This final result will then be thresholded with activation sigmoid binary and the result is named $\mathrm{zl}$. In the second neuron, $\mathrm{x} 1$ is multiplied by $\mathrm{v} 12$ and $\mathrm{x} 2$ multiplied by v22. The result is then summed up and added by v02, then the total sum was added to thresholded with activation binary sigmoid. Results on neurons 2 are called $z 2$. Then the above steps are reused on neuron 3 and neuron 4 using input $\mathrm{z} 1$ and $\mathrm{z} 2$, while the weight w01, w02, w11, w12, w21, as shown in Fig. 6.

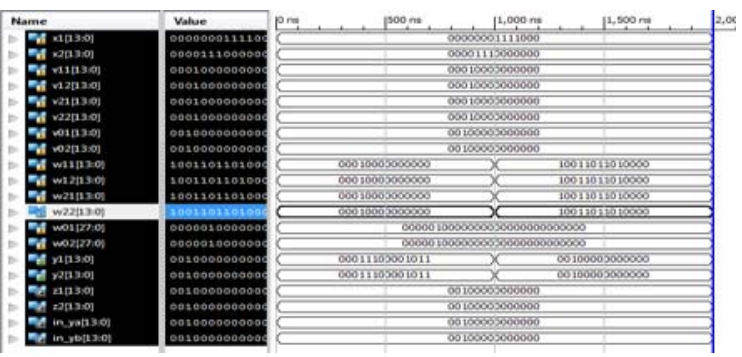

Fig. 6 Feedforward propagation simulation results

The output of Feedforward propagation is then thresholded to simplify the output with a threshold of 0.5 where the value above 0.5 is ' 1 ' and below 0.5 means ' 0 '.

\section{RESULTS AND DISCUSSION}

In the implementation test performed 40 times the test for each size in accordance with that has been designed with 40 pairs of blood sample images. The tests were performed on $32 \times 32,48 \times 48,64 \times 64,80 \times 80$ and $96 \times 96$ pixel sizes. Based on the results of scenariol the test is done based on two parameters, that is comparison of resolution with mean number of bits ' 1 ' and comparison of resolution with median number of bits '1' as shown on Fig.7 and Fig.8.

From the test results obtained respectively resolution $(32 \times 32,48 \times 48,64 \times 64,80 \times 80$ and $96 \times 96)$ obtained the value of accuracy with the formation of patterns based on the comparison of resolution with median number of bit' 1 'gives almost the same value. This is due to the comparison value based on the median number of bits ' 1 ' using the mean value of the whole data, so it is most likely that the middle value is a threshold that distinguishes the number of bits ' 1 ' from coagulated images with non-clumps. The mean value uses the overall mean value of the data, if there is any data of extreme value (very small or very large) it will affect the mean value itself, but in the training image there is nothing too extreme as to provide a better mean value. So from the two groupings are not too much different in its threshold.

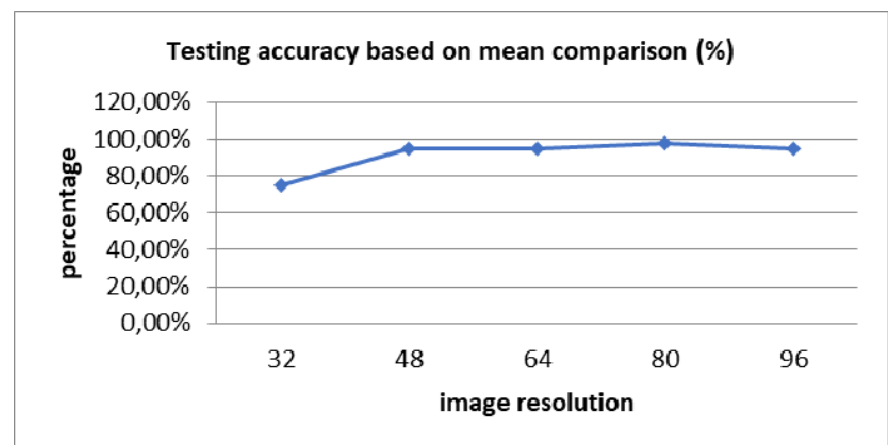

Fig. 7 Accuracy result of resolution comparison to number of ' 1 ' mean.

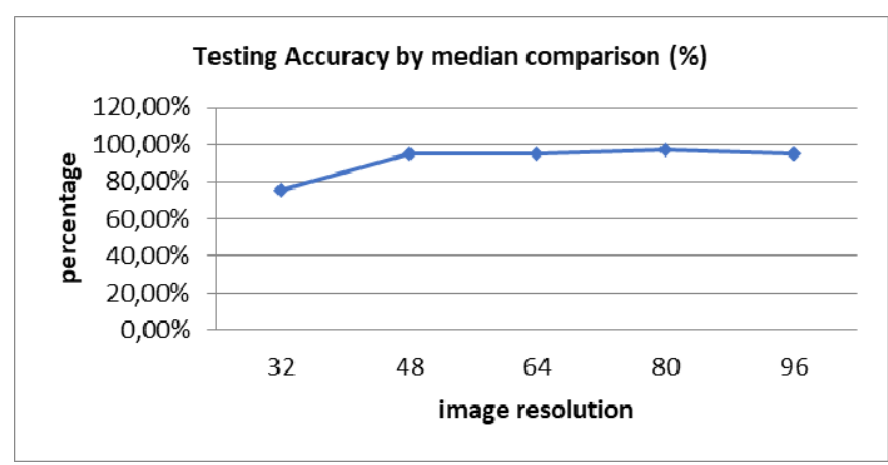

Fig. 8 Accuracy result of resolution comparison to number of ' 1 ' median.

In addition to the large difference in percentage accuracy between pattern testing based on comparison with the mean and median, it can be seen also the movement of percentage values along with the increase in resolution used. The percentage of accuracy gives an indication of an indeterminate value along with the greater the resolution used, whereas the information obtained from the image would be more and more with the enlarged resolution. Therefore, the number of '1' bits in the image may not be the most appropriate reference to use in determining the pattern of image features.

Error detection can also be caused due to improper threshold on the pattern determination so that there are some images of blood samples are wrong in determining the pattern characteristics. It is also caused by the influence from outside the system, that is not done the determination of antisera fluid size rule with blood when mixing. If antisera liquid more than blood then causes the result of mixing becomes dilute and the resulting image also becomes unclear, whereas when the 
antisera liquid is given a little it will make the mixing with the blood becomes thick so that the image looks darker. This can cause problems when a Grayscale image process is made to Black and White with the graylevel used.

\section{CONCLUSIONS}

1. An ANN functional simulation with backpropagation algorithm targeting on FPGA can only be done on feedforward propagation of backpropagation algorithm.

2. In ANN forward propagation testing of backpropagation algorithm targeting fpga to determine blood type from feature grouping with comparison of mean value obtained accuracy of $75 \%, 95 \%, 95 \%, 97,5 \%$ and $97,5 \%$. While the use of median comparison ratio obtained accuracy of $75 \%, 95 \%, 95 \%, 97.5 \%$ and $95 \%$. (each sequence with $32 \times 32,48 \times 48,64 \times 64,80 \times 80$, and 96x96 resolutions).

3. The result of accuracy with ratio of median value is almost same with comparison of mean value, accuracy will be increasing with resolution magnification in forward propagation algorithm implementation, test result depends very much on characteristic pattern specified

4. The value of test accuracy is influenced by the internal factors of the system (features determination) as well as external factors (the absence of rules in the administration of antisera liquid).

\section{ACKNOWLEDGMENT}

We would like to thank to Electronic and Telecommunication Departement and Diploma of Telecommunication Engineering, Telkom University for facilitate all the materials and required resources for this research.

\section{REFERENCES}

[1] H. P. I. Wijaya, Z. Abidin, and E. Sugiharti, "Implementasi Jaringan Syaraf Tiruan Backpropagation untuk Pengenalan Citra Digital Menggunakan Deteksi Tepi," UNNES J. Math., vol. 3, no. 1, pp. 76-83, 2014.

[2] S. Aryadhi, "Identifikasi golongan darah manusia dengan teknik pengolahan citra menggunakan metode jaringan syaraf tiruan," Universitas Indonesia, 2008.

[3] Budiana and J. Adler, "IDENTIFIKASI GOLONGAN DARAH MANUSIA SISTEM ABO MENGGUNAKAN JARINGAN SYARAF TIRUAN," Unikom, 2016.

[4] T. Szabi and G. Horvath, "An Efficient Hardware Implementation of Feed-Forward Neural Networks *," Appl. Intell., vol. 21, pp. 143-158, 2004.

[5] H. Murwati, I. Wahidah, and D. Darlis, "PERANCANGAN DAN IMPLEMENTASI ARTIFICIAL NEURAL NETWORK ( ANN) PADA FPGA UNTUK MENENTUKAN JENIS GOLONGAN DARAH," Universitas Telkom, 2011.

[6] Iswahyudi, M. A. Auliq, and D. Irawan, "Pembuatan sistem penentuan golongan darah manusia berbasis mikrokontroler avr atmega 8535," Universitas Muhammadiyah Jember, 2016.

[7] M. Maitra, R. K. Gupta, and M. Mukherjee, "Detection and Counting of Red Blood Cells in Blood Cell Images using Hough Transform," Int. J. Comput. Appl., vol. 53, no. 16, pp. 975-8887, 2012.

[8] S. L. Bhagavathi and S. Thomas Niba, "An automatic system for detecting and counting rbc and wbc using fuzzy logic," $A R P N J$. Eng. Appl. Sci., vol. 11, no. 11, pp. 6891-6894, 2016. 